\title{
MÍDIA, GÊNEROS DO DISCURSO E TRANSGRESSÃO*
}

\author{
Glaucia Muniz Proença Lara**
}

Resumo: À luz da concepção de gêneros do discurso de Mikhail Bakhtin, acrescida das contribuições de estudiosos da área de análise do discurso, examinamos, no presente artigo, três textos da mídia, de diferentes gêneros (dois anúncios publicitários e uma tira humorística), procurando enfocá-los do ponto de vista da transgressão, tomada como uma quebra de expectativa ou uma ruptura (desvio, deslocamento) de algum componente do conjunto de restrições - ou de regularidades - inerentes a um dado gênero. Nossa análise aponta para dois tipos diferentes de transgressão: a "intertextualidade intergenérica", quando ocorre uma hibridização ou uma mescla de gêneros em que um assume a funçāo ou a forma de outro, e a "intertextualidade intragenérica", em que essa mescla de gêneros se dá no interior de um gênero maior, que não é afetado.

\section{Introdução ${ }^{1}$}

A reflexão sobre os gêneros do discurso remonta à Antigüidade Clássica, mais especificamente, a Aristóteles,

* Texto entregue para publicação em setembro de 2005 e, posteriormente, apresentado durante o "IV Seminário de Metodologia do Ensino de Língua Portuguesa da FEUSP" (São Paulo, SP - 16 a 18 de novembro de 2005).

** Professora da Faculdade de Letras da UFMG.

1 Agradecemos ao Professor Doutor Luiz Antônio Marcuschi a leitura, em primeira mão, deste artigo. 
que se serviu de duas tradições - a Retórica (com a célebre tripartição entre gênero judiciário, deliberativo e epidíctico) e a Poética - para abordar a questão. Com o declínio da Retórica, os gêneros e subgêneros literários passaram para o primeiro plano, fazendo com que a noção de gênero passasse a ser tratada, essencialmente, no quadro da tradição literária e, paralelamente, fosse negligenciada pelas teorias lingüísticodiscursivas.

Tal situação alterou-se apenas no século $X X$, quando Mikhail Bakhtin, partindo de uma discussão mais ampla em torno da noção de discurso, retomou a discussão dos gêneros ${ }^{2}$, desencadeando, a partir de então, um grande número de reflexões teóricas que ainda hoje conservam seu grau de originalidade. Quaisquer que sejam as leituras dos gêneros do discurso de Bakhtin, é certo que o tema encontra eco ainda nos dias de hoje, tornando-se não apenas uma referência para grande parte dos pesquisadores das ciências da linguagem (como atesta o grande número de trabalhos, vinculados a disciplinas que vão da Teoria Literária à Análise do discurso ${ }^{3}$ e que, via de regra, retomam, em maior ou menor grau, as concepções do teórico russo), mas também para o ensino de línguas (como comprova a recente incorporação da noção de gêneros, de inspiração bakhtiniana, nos Parâmetros Curriculares Nacionais, 1996).

2. Referimo-nos às obras Marxismo e filosofia da lingungem (BAKHTIN, 1990 - 1 $^{\text {a }}$ edição: 1929) e Estética da Criação Verbal (BAKNTIN, 2000 - 1ª edição: 1979). Ao abordar temas como fala, enunciação e interação verbal em MFL, Bakhtin traça as grandes linhas de investigação da lingüística centrada no discurso, prenunciando o conceito de gêneros, ao qual dedicará todo um capítulo em ECV.

3 Citamos, nesse sentido, o livro Gêneros: reflexões em análise do discurso (MACHADO; MELLO, 2004), publicado pelo Núcleo de Análise do Discurso e pelo Programa de Pós-Graduação em Estudos Lingưísticos da Faculdade de Letras/UFMG, cujos artigos, em grande parte, serviram de apoio para nossa discussão sobre os gêneros do discurso e sobre a questão da transgressão (vide referências). 
Dada a importância de Bakhtin, no çontexto atual dos estudos de gêneros e, particularmente, no âmbito de uma análise do discurso que visa a articular as "falas" e os "lugares" que as autorizam (MAINGUENEAU, 2004: 43), partamos das reflexões propostas pelo autor em Estética da Criação Verbal para, em seguida, falar de transgressão.

\section{A noção de gênero na teoria bakhtiniana}

Segundo Bakthin, quando o locutor utiliza a língua numa determinada "esfera da atividade humana", ele o faz sob a forma de "enunciados (orais e escritos) concretos e únicos" que passam a refletir as condições específicas e as finalidades de cada uma delas. O enunciado é considerado, portanto, como "a unidade real da comunicação verbal", definição essa que o aproxima da concepção atual de texto.

Nessa perspectiva, os enunciados refletem as condições específicas e as finalidades de cada uma dessas esferas por seu "conteúdo temático" (que remete aos assuntos das diferentes atividades humanas), por seu "estilo" (seleção operada nos recursos lexicais, fraseológicos e gramaticais da língua) e por sua "construção composicional" (que corresponde, grosso modo, à estrutura textual e às relações que se instituem entre os parceiros da comunicação) (BAKHTIN, 2000: 279-287).

As esferas de utilização da língua passam, pois, a compor um "repertório de tipos relativamente estáveis de enunciados", que Bakhtin chama de "gêneros do discurso". Esses gêneros são considerados inesgotáveis pela riqueza e variedade que representam a partir das inúmeras esferas de atividades humanas e pela capacidade de ampliar-se a partir dos tipos estáveis. $\mathrm{O}$ autor exemplifica a heterogeneidade dos gêneros do discurso, afirmando que eles vão da réplica mais simples de um diálogo às manifestações literárias 
(provérbios, contos, poemas, romances etc.), passando pelos relatos familiares (a carta, os bilhetes, os postais etc), pelas formas padronizadas dos documentos oficiais na sua forma imperativa (atas, relatórios, declarações, ordens militares etc) e pelas exposições científicas (artigos, dissertações, teses e outras formas) (BAKHTIN, 2000: 279).

Em termos de complexidade, Bakhtin distingue os gêneros do discurso "primários", oriundos da comunicação verbal espontânea e, por isso, mais simples, dos "secundários" - oromance, o teatro, o discurso científico, o discurso ideológico - que, formados a partir dos gêneros primários, aparecem em circunstâncias de uma comunicação cultural mais complexa e relativamente evoluída, sobretudo na modalidade escrita (BAKHTIN, 2000: 281-287).

Ora, a definição de gênero proposta por Bakhtin atesta uma certa estabilidade, ou normatividade, nas produções verbais dos falantes. No entanto, o autor deixa claro, desde o início, que essa "invariabilidade" acompanha a dinamicidade da fala, única em sua realização. Além disso, ao caracterizar os gêneros como tipos "relativamente" estáveis de enunciados, abre espaço para a transgressão ou o desvio, questão que nos interessa mais de perto no presente trabalho. Em outras palavras, se os gêneros, enquanto entidades sócio-discursivas, contribuem para ordenar e estabilizar as atividades comunicativas do dia-a-dia, eles não são instrumentos estanques e enrijecedores da ação criativa; ao contrário, são fenômenos, acima de tudo, maleáveis e dinâmicos que surgem, modificam-se e mesmo desaparecem, em função das necessidades e das atividades (relacionadas às diferentes esferas de utilização da língua) presentes numa dada sociedade.

Nessa perspectiva, somos levados a assumir que um gênero se situa na "zona de tensão" entre um conjunto 
de restrições - ou de regularidades - e um horizonte de possibilidades - ou de variações possíveis, o que implica um sujeito capaz de operar sobre o convencional, sobre o previamente instituído, assumindo-o ou subvertendo-o, em busca da construção de outros (novos) efeitos de sentido. Essa questão passa, naturalmente, pela existência de gêneros mais (ou menos) padronizados. O próprio Bakhtin admitia que há gêneros mais aptos para refletir o estilo individual (como os literários) e outros que requerem uma forma padronizada e, portanto, associam-se ao estilo lingüístico ou funcional, isto é, "ao estilo de um gênero peculiar a uma dada esfera da atividade e da comunicação humana" ${ }^{4}$ (BAKHTIN, 2000: 283).

\section{Gênero: entre a coerção e a ruptura}

A dificuldade de abordar a noção de desvio ou transgressão é corolária da própria complexidade e extensão do conceito de gênero. Afinal de contas, nem sempre é fácil decidir sobre limites entre um e outro gênero, reconhecer subgêneros no interior de um gênero maior e mesmo arrolar critérios que permitam enquadrar um determinado texto/ discurso num gênero " $\mathrm{x}$ " e não num gênero " $\mathrm{y}$ ".

4 Nessa perspectiva, Maingueneau propõe quatro modos de genericidade instituída, que vão do mais padronizado (modo I) ao mais criativo (modo IV). O modo I implica gêneros instituídos que não estão - ou estão pouco - sujeitos à variação (fichas administrativas, catálogo telefônico, registros de cartório etc). No modo II, encontram-se os gêneros que seguem uma cenografia preferencial ou esperada, mas toleram desvios (por exemplo, um programa político-eleitoral em forma de carta ou um guia de viagens apresentado como uma conversa entre amigos). O modo III inclui gêneros (como publicidades, músicas e programas de tv) que incitam à inovação, não apresentando, portanto uma cenografia preferencial (embora, com o tempo, possam tornar-se estereotipados). No modo IV, finalmente, situam-se os gêneros propriamente autorais, como os literários, por exemplo, para os quais a própria noção de "gênero" se torna problemática (MAINGUENEAU, 2004: 50-53). 
Essa dificuldade nos leva a admitir que a concepção de gênero apresenta uma "mobilidade prática" ou uma "funcionalidade intuitiva" inversamente proporcional à sua clareza conceitual. Ou seja, mesmo não sabendo explicitar o que entendem por gêneros, os usuários são capazes de reconhecêlos e de operar, de forma produtiva, com os diferentes gêneros que circulam socialmente, percebendo, inclusive, as transmutações que sofrem e as "quebras de expectativa" (ou "rupturas de contratos") que os afetam (MARI; SILVEIRA, 2004: 65).

Tal questão, por sua vez, remete ao pressuposto básico, assumido pela grande maioria dos estudiosos que.tratam a língua em seus aspectos discursivos e enunciativos: o de que "é impossível se comunicar verbalmente a não ser por algum gênero", assim como é impossível se comunicar verbalmente a não ser por meio de textos, entendidos como a realização ou a materialização de discursos em situações institucionais, históricas, sociais e ideológicas (MARCUSCHI, 2002: 22-24).

Na mesma direção de Marcuschi, Rastier (apud DIAS, 2004) propõe o gênero como o princípio organizador de um texto, ou seja, somente no interior de um gênero é possível caracterizar e analisar um texto. No seu entender, as práticas de linguagem ganham significação e estabilidade no gênero, estabilidade essa garantida por uma normatividade. É ela que permite que determinados textos circulem com regularidade e sejam reconhecidos como instrumentos de regulação das práticas de convivência social. Assim, todo texto, tendo em vista seu gênero, situa-se numa prática e é nessa prática que ele é "reconhecido".

No entanto, é preciso admitir (como, aliás, já o fizemos) que os gêneros, dada a sua plasticidade, estão, ao mesmo tempo, submetidos aos movimentos dinâmicos das sociedades em que circulam e dos sujeitos, que os colocam constantemente 
em transformação. É por aí que se insinua a já citada noção de transgressão ou de desvio.

Para Charaudeau, na transgressão de gêneros, isto é, quando percebemos índices de reconhecimento de dado gênero, mas, ao mesmo tempo, detectamos formas que não são esperadas, a questão que se coloca é saber o que é "desrespeitado": 1) as restrições situacionais, responsáveis pelo contrato de comunicação entre os parceiros, envolvendo elementos, como finalidade (visada), identidade dos participantes, propósito (e sua estruturação temática) e as circunstâncias que precisam as condições materiais da comunicação (por exemplo, rádio, imprensa, televisão, para as mídias); 2) as restrições discursivas, que incidem sobre os modos enoncivos (descritivo, narrativo, argumentativo), enunciativos (alocutivo, elocutivo, delocutivo), de tematização (temas e subtemas) ou de semiologização (verbal e/ ou visual); 3) as restrições formais, relacionadas aos diferentes aspectos de organização textual: mise-en-scène textual (por exemplo, a composição das páginas de um jornal e sua divisão em partes), a composição textual interna (a articulação entre as partes, o jogo de retomadas e reenvios de uma parte à outra), a fraseologia (o emprego recorrente de fórmulas, expressões fixas etc), a construção gramatical (relacionada ao aparelho formal da enunciação: modalização, pronominalização, anaforização, construções ativas, passivas ou impessoais etc) e, nos gêneros mais padronizados, o domínio das recorrências lexicais (repetição, isotopia lexical). Há, pois, diferentes tipos de transgressão, cuja incidência entre os três níveis de restrições é variável (CHARAUDEAU, 2004: 32-33).

Souza, por sua vez, admitindo que é a partir do contrato comunicacional que haverá uma regularidade de gêneros de discursos (já que os gêneros são determinados pela articulação das restrições impostas ao ato de comunicação), entende a 
transgressão como a quebra desse contrato comunicacional, quebra essa que infringe uma das restrições desse contrato, mas preserva a maior parte da estrutura do gênero. É isso, segundo ele, que permite que o gênero transgredido seja reconhecido e preservado no ato comunicacional (SOUZA, 2004: 197). Já para Machado, "um gênero é transgressivo quando ele 'ousa' amalgamar em si diferentes tipos de discursos que tinham, em suas respectivas origens, um objetivo diferente daquele que vão assumir quando reunidos em um só" (MACHADO, 2004: 78).

Marcuschi, finalmente, apoiado em Ursula Fix, fala não de transgressão, mas de "intertextualidade inter-gêneros" quando ocorre uma hibridização ou uma mescla de gêneros em que um assume a função ou a forma de outro (por exemplo, um artigo de opinião no formato de um poema). $O$ autor destaca ainda que há gêneros mais propensos do que outros a uma intertextualidade inter-gêneros, como é o caso da publicidade, que busca, na subversão da ordem instituída, um novo enquadramento de um dado produto de modo a seduzir o outro (leitor/espectador) (MARCUSCHI, 2002: 3031). É exatamente desse domínio que vêm os dois textos que analisaremos a seguir: uma propaganda de bebida e uma outra do cartão VISA, ambos publicados na mídia impressa (revistas). Lembramos que, na acepção de Maingueneau (vide nota 2), os anúncios publicitários se enquadrariam nos gêneros instituídos no modo III, ou seja, aqueles cuja natureza é incitar a inovação.

\section{A transgressão em textos publicitários}

A idéia de transgressão (ou de intertextualidade inter-gêneros) passa, na perspectiva dos autores citados, por uma "quebra de expectativa" ou pela ruptura (desvio, deslocamento) de algum componente do conjunto de restrições - ou de regularidades - inerentes a um dado gênero. 
Na primeira propaganda (Texto $1 \div$ Anexo), anunciase um produto (uma cachaça) sob a forma de um verbete de dicionário. Mantém-se, naturalmente, a função do texto: convencer o leitor a comprar (e a consumir) o produto anunciado, tanto assim que os dois enunciados finais: "À venda nas melhores casas do ramo." e "Aprecie com moderação." Remetem, novamente, às coerções do gênero anúncio publicitário (enunciado 1) e, mais especificamente, do subgênero anúncio publicitário de bebidas (enunciado 2). No entanto, o leitor, que, no geral, esperaria encontrar um anúncio da singularidade do produto ou uma exaltação de suas qualidades intrínsecas (por exemplo, seu sabor) ou os resultados benéficos de sua utilização (por exemplo, prazer) se surpreende com a forma nada convencional de um verbete de dicionário, um gênero de texto padronizado, que procura, via definição, criar um efeito de sentido de objetividade e mesmo de cientificidade.

Houve, pois, numa certa medida, a quebra do contrato comunicacional entre o enunciador (instância produtora da publicidade) e o enunciatário (instância consumidora) que, embora preservando, a função do gênero "publicidade" - caracterizado por uma "visada" dominante de incitação, construída duplamente por um "fazer/dever acreditar" (CHARAUDEAU, 2004: 23) - infringe uma de suas restrições: a forma ou a configuração textual ${ }^{6}$. Naturalmente, a escolha

5 As visadas correspondem a uma intencionalidade psico-sócio-discursiva que determina a expectativa da troca linguageira. Na visada de incitação, o $e u$ quer "mandar fazer", mas, como não está em posição de autoridade, deve "fazeracreditar" (por persuasão ou sedução) ao tu que ele será o beneficiário de seu próprio ato. O tu está, pois, em posição de "dever acreditar" que, se ele age, é para o seu bem (CHARAUDEAU, 2004: 23).

6 Como o predomínio da função supera a forma na determinação do gênero (cf. MARCUSCHI, 2002: 23), a "mescla" de gêneros, nesse caso, não oferece maiores dificuldades de interpretação para o leitor, que tende a reconhecer o texto como um anúncio publicitário, apesar da forma um tanto inusitada. 
do novo gênero não se dá por acaso: o "suporte" em que o texto se encontra, uma revista financiada pelas TAM Linhas Aéreas, embora traga o sugestivo título de "Almanaque Brasil de Cultura Popular" (grifo nosso), pressupõe um leitor elitizado, familiarizado com dicionários.

Assim, a subversão da ordem genérica instituída, dando ào produto à venda um novo enfoque, pretende seduzir um leitor mais exigente (ou até mais culto), que seja capaz de reconhecer no gênero transgressor (o verbete de dicionário) o gênero transgredido (o anúncio voltado para a comercialização de um produto), uma vez que as restrições situacionais e discursivas são, no geral, mantidas ${ }^{7}$. A própria "mistura" de gêneros torna-se, pois, uma estratégia ou manobra argumentativa num discurso que (sobre)vive do seu poder de interpelar e influenciar o outro (leitor/espectador), como é o caso do discurso da propaganda.

No segundo texto (Texto 2 - Anexo), ocorre novamente uma mescla ou hibridização de gêneros: de um anúncio publicitário de aquisição de um produto (o cartão VISA) para uma receita de cozinha. Assim como no primeiro caso, temos um texto sincrético, em que se articulam o verbal e o não-verbal. Neste, encontram-se elementos que prenunciam. uma receita culinária: há ingredientes, dispostos sobre uma superfície lisa (provavelmente uma mesa). Porém, o texto verbal não retoma os ingredientes do texto visual; no "modo

$7 \quad$ É claro que podemos pensar numa alteração do tipo textual dominante (o que está ligado às restriçōes discursivas apontadas por Charaudeau), já que ocorre a passagem de um discurso argumentativo, com alto grau de persuasão (anúncio publicitário), para um discurso de cunho descritivo (identifica-se e descreve-se um dado objeto), com um teor persuasivo mais velado (verbete de dicionário). Se pensarmos, por outro lado, na identidade dos parceiros (anunciante/ consumidor), no propósito (agir sobre o sonho de bem-estar do indivíduo) ou as circunstâncias que precisam as condições materiais de comunicação (imprensa), vemos que essas restrições praticamente não se alteram na passagem de um gênero ao outro. 
de fazer", construído, como numa receita, com frases curtas, no imperativo afirmativo (modalização alocutiva: tempere, escolha, corte, frite etc) e incluindo, no final, um sintomático Bom apetite!, os elementos são outros, implicando a passagem de um estado de não-prazer para um estado de prazer (ou de um estado de disjunção para um estado de conjunção com o prazer) ${ }^{8}$, proporcionado por tudo aquilo que o produto anunciado - um cartão de crédito - permite fazer/comprar. O slogan (elemento típico da fraseologia do discurso publicitário): Porque a vida é agora, disposto em letras miúdas ao lado do logotipo do produto (que aparece apenas no final da propaganda) e introduzido por um operador argumentativo de explicação (porque), pretende ser uma justificativa (sintética) das ações propostas, articulando-as ao "objeto" do querer/poder-fazer: o cartão VISA.

"Para o leitor que esperaria encontrar um discurso de exaltação do cartão VISA (por exemplo, vantagens em relação a outros cartões de crédito; benefícios, como praticidade e rapidez, nas compras), com o uso predominante do modo argumentativo, encontra, na verdade, uma descrição de ações que, se não permitem a construção do objeto de valor "prato a ser degustado", possibilitam, por outro lado, a partir da aquisição de um outro objeto de valor, já existente e que circula entre sujeitos - o cartão VISA -, viver a "paixão" do prazer (divertir-se, vestir-se bem, ir a um bom restaurante, em companhia agradável etc)."

8 Servimo-nos aqui de algumas categorias tomadas de empréstimo à semiótica greimasiana. 
Os efeitos de sentido do anúncio publicitário são, pois, re-significados numa receita de cozinha ou, melhor dizendo, num simulacro de receita de cozinha, já que, embora a construção interna do texto obedeça aos ditames de uma receita de cozinha (ações sucessivas, ordenadas, que levam a um resultado final) e os verbos utilizados sejam efetivamente aqueles que constariam de tal gênero ${ }^{9}$, os ingredientes são outros (há, inclusive, um desacordo entre o que é enunciado, no texto verbal, e o que é mostrado, no texto visual). Ocorre, pois, uma hibridização de gêneros que mantém, no entanto, a função primeira do texto: agir sobre o outro (através de uma visada dominante de incitação), levando-o a adquirir ou a usar um dado produto.

A transgressão se dá novamente sobre os elementos formais (e talvez discursivos - como observamos na nota 7, em relação ao texto 1 - já que se passa do modo argumentantivo para o modo descritivo, mantendo-se, no entanto, o objetivo maior de persuasão, ainda que de forma mais sutil ou tênue). $O$ contrato de comunicação entre os parceiros (instância anunciante e instância consumidora) e o propósito maior (agir sobre o sonho de bem-estar do indivíduo) se mantêm, apesar do desvio ou da quebra de expectativa, representada pela passagem do gênero anúncio publicitário para o gênero receita de cozinha. Também aqui a escolha do gênero transgressor não é aleatória: o suporte - uma revista sobre a vida de artistas e famosos (Quem acontece) - pressupõe um público preferencialmente feminino, mais afeito, portanto, a receitas de cozinha, o que vem reforçado pelo toque sutil "Tempere

9 Charaudeau coloca as receitas de cozinha entre os textos fortemente marcados que, dessa forma, constroem um léxico especializado. No caso desse simulacro de receita - a propaganda do cartão VISA - os verbos, como dissemos, são efetivamente os do campo lexical da culinária (fritar, juntar, misturar, temperar etc), mas não os "ingredientes" e é exatamente aí que reside a criatividade do texto (CHARAUDEAU, 2004: 36). 
com uma roupa apimentada" (grifo nosso), elemento mais ligado ao universo de sedução da mulher.

Tanto o texto 1 quanto o texto 2 são exemplos de transgressão de gêneros-ou de intertextualidade inter-gêneros - visto que temos um gênero funcional (anúncio publicitário, em ambos os casos) com o formato de outros (um verbete de dicionário e uma receita de cozinha, respectivamente). Tratase, como já observamos, de desenquadrar produtos (uma cachaça, um cartão de crédito) do seu enquadre normal, para, sob um novo enfoque, levar o leitor a distingui-los, de forma mais nítida, no mar de oferta de produtos que nos cercam no dia-a-dia.

Vejamos agora um outro caso, também no domínio da mídia impressa, mas de um outro gênero: tira humorística, publicada no jornal Folha de São Paulo (Texto 3 - Anexo). Aqui ocorre, como nos textos 1 e 2, um desvio, uma quebra de expectativa (já que os gêneros, como dissemos, funcionam como um "contrato de comunicação" entre os parceiros da troca linguageira, a partir da observância de um conjunto de princípios socialmente pré-estabelecidos). Essa transgressão é, no entanto, de uma outra ordem: ela ocorre não entre gêneros (um assumindo a forma ou a função de outro), mas no interior de um mesmo gênero (maior), que não chega a ser afetado.

\section{A transgressão na tira humorística: uma intertextualidade intragenérica?}

Antes de mais nada, cabe lembrar que o humor vive, em grande parte, da sua capacidade de transgredir, com uma finalidade básica: o "fazer rir". Além disso (ou por causa disso), abre um espaço maior para o exercício da subjetividade, ou seja, favorece a emergência de estratégias discursivas típicas de uma intervenção intencional mais efetiva do sujeito. $O$ 
humor deve, pois, ser pensado como "um certo tipo de efeito de sentido baseado na 'incongruência' de certos elementos, produzido a partir de um trabalho específico do sujeito sobre as determinações formais e históricas constitutiva da materialidade dos diferentes sistemas semióticos" (MENDES, 2004: 131).

$\mathrm{Na}$ tira apresentada, é a "incongruência" ou a transgressão na fala do médico (prenunciada, nos quadrinhos 1 e 2 como se inscrevendo no gênero consulta médica e, passando, no quadrinho 3, para o gênero receita de cozinha) que suscita o humor. Temos, assim, uma mixagem de gêneros interna ao texto, a partir da mudança de papéis desempenhados pelas personagens que dialogam: da relação profissional médico/ paciente eles passam para uma relação quase de cumplicidade entre amigos, que falam de assuntos triviais, como culinária.

Há, pois, uma quebra de expectativa quanto à manutenção do gênero consulta médica, motivada pela ruptura do contrato conversacional entre médico e paciente ${ }^{10}$. Assim, $o$ "dever" proibitivo das duas falas iniciais do médico (Você vai ter que cortar a carne... cortar o bacon, a pimenta, a lingüiça), que poderiam ser parafraseadas por "Você está proibido de comer carne, de comer bacon, pimenta, lingüiça" (prescrição médica), é re-significado, no último quadrinho, como uma instrução necessária para a correta confecção de um prato (receita de cozinha). Passa-se, dessa forma, de uma visada de prescrição (mandar fazer), de alguém que tem autoridade para isso (o médico) para uma visada de instrução, que pretende levar o outro a um dever saber-fazer, já que o "eu" (agora despido do

10 O humor freqüentemente se vale da passagem de uma isotopia (entendida como "a recorrência de traços semânticos ao longo do discurso") a outra (FIORIN, 1989: 83). No caso da tira analisada, a isotopia médica inicial dá lugar a uma isotopia culinária, o que permite uma dupla leitura, criando o efeito de humor. 
seu papel profissional/social) está legitimado para transmitir um saber fazer ao " $t u^{\text {": }}$ é ele que detém a receita do prato.

Essa transgressão (consulta médica $\rightarrow$ receita de cozinha), no entanto, não afeta o gênero tira humorística, nem na função (divertir o leitor), nem na forma (uma seqüência de quadrinhos que narram uma história). Pelo contrário, é ela que cria o efeito de sentido necessário ao "fazer rir", reforçando, portanto, o gênero em questão. Em outras palavras: se o contrato de comunicação entre os parceiros da história narrada é rompido, o mesmo não se pode dizer do contrato entre produtor da tira e leitor, que é mantido e reforçado pela própria ruptura da história. A transgressão não é, pois, "externa" ao texto (um gênero assume a forma ou a função de outro: um anúncio publicitário "transforma-se" em verbete de dicionário ou em receita de cozinha), mas "interna" a ele: ocorre a co-existência ou a sobreposição de diferentes gêneros em um mesmo texto, preservando-se, no entanto, o gênero maior (tira humorística). Se, no primeiro caso, temos uma intertextualidade inter-gêneros ou intergenérica, parecenos possível propor, no segundo, uma intertextualidade intragenérica.

\section{Considerações finais}

Os gêneros do discurso, nạo sendo fruto de invenções individuais, mas formas socialmente construídas em práticas comunicativas, funcionam como geradores de expectativas de compreensão mútua (MARCUSCHI, 2002: 35). Não são, no entanto, algo pronto e acabado, mas conjuntos de regularidades discursivas que, como tais, se prestam a deslocamentos, desvios e rupturas. Essas possibilidades de transgressão foram, como dissemos, previstas pelo próprio Bakhtin, que, ao propor os gêneros como tipos relativamente 
estáveis de enunciados, elaborados pelas diferentes esferas de utilização da língua, previa uma margem possível de manobra na construção desses "artefatos".

É claro que o nível de coerção varia de gênero para gênero, indo desde os mais normatizados (gêneros instituídos de modo I, como a correspondência comercial e oficial, o catálogo telefônico ou os registros de cartório) até os que oferecem mais liberdade para a emergência da criatividade (gêneros instituídos de modo IV, como os textos literários, em geral).

Os três textos que analisamos, em princípio, se inscreveriam no modo III - gêneros que incitam à inovação, não apresentando uma cenografia preferencial - , porém, na medida em implicam um sujeito-autor, que trabalha estrategicamente com e sobre as regularidades convencionais, subvertendo-as (externa ou internamente), em função da produção de efeitos de sentido intencionais, caminhariam já para o modo IV (gêneros propriamente autorais). Afinal de contas, os textos são dinâmicos, e os limites entre os gêneros podem ser mais tênues e complexos do que supomos.

A questão fundamental que se coloca é, pois, encontrar o ponto de equilíbrio entre as coerções (mais ou menos) impostas pelos gêneros e a liberdade de que o sujeito falante dispõe para operar com elas. Como diz Charaudeau, "aceitar que existem gêneros é reconhecer que a produção linguageira é submetida a restrições. Mas em que nível estas restrições intervêm?" (CHARAUDEAU, 2004: 19). O presente artigo tentou ser uma resposta (pelo menos, parcial) para essa questão.

Résumé: A la lumière de la conception des genres du discours chez Mikhail Bakhtin, à laquelle s'ajoutent les contributions de nombre de chercheurs dans le domaine de l'analyse du discours, nous nous proposons d'analyser, dans cet article, trois textes issus des médias appartenant ì différents genres, 
dont deux publicités et une bande dessinée humoristique, sous l'optique de la transgression, prise comme une rupture de l'attente (déplacement) ou d'un élément dans l'ensemble des restrictions - ou régularités - inhérentes à un genre donné. Notre analyse indique deux types distincts de transgression: l'intertextualité inter-générique, lorsqu'il y a une hybridation ou un mélange de genres où un genre assume la fonction ou la forme d'un autre, et l'intertextualité intra-générique, où ce mélange de genres se donne à l'intérieur d'un genre prédominant, qui, à son tour, n'est pas déstabilisé.

\section{Referências bibliográficas}

BAKHTIN, Mikhail. Marxismo e filosofia da linguagem. São Paulo: Hucitec, 1990.

Fontes, 2000.

. Estética da criação verbal. 3. ed. São Paulo: Martins

CHARAUDEAU, Patrick. Visadas discursivas, gêneros situacionais e construção textual. In: MACHADO, Ida Lúcia; MELLO, Renato de. (orgs.). Gêneros: reflexões em análise do discurso. Belo Horizonte: NAD/POSLIN/FALE-UFMG, 2004.

DIAS, Luiz Francisco. Modos de enunciação e gêneros textuais: em busca de um novo olhar sobre gêneros de texto. In: FONSECA, M. C. (org.). Em torno da lingua(gem): questões e análises. Vitória da Conquista: UESB, 2004 (no prelo).

FIORIN, José Luiz. Elementos de análise do discurso. São Paulo: Contexto, 1989.

MACHADO, Ida Lúcia. A paródia, um gênero transgressivo. In: ; MELLO, Renato de. (orgs.). Gêneros: reflexões em análise do discurso. Belo Horizonte: NAD/POSLIN/FALEUFMG, 2004. 
MACHADO, Ida Lúcia; MELLO, Renato de. (orgs.). Gêneros: reflexões em análise do discurso. Belo Horizonte: NAD/POSLIN/ FALE-UFMG, 2004.

MAINGUENEAU, Dominique. Diversidade dos gêneros de discurso. In: MACHADO, Ida Lúcia; MELLO, Renato de. (orgs.). Gêneros: reflexões em análise do discurso. Belo Horizonte: NAD/POSLIN/FALE-UFMG, 2004.

MARCUSCHI, Luiz Antônio. Gêneros textuais: definição e funcionalidade. In: DIONÍSIO, Ângela P.; MACHADO, Anna Rachel; BEZERRA, M. Auxiliadora (orgs.). Gêneros textuais e ensino. Rio de Janeiro: Lucerna, 2002.

MARI, Hugo; SILVEIRA, José Carlos C. Sobre a importância dos gêneros discursivos. In: MACHADO, Ida Lúcia; MELLO, Renato de. (orgs.). Gêneros: reflexões em análise do discurso. Belo Horizonte: NAD/POSLIN/FALE-UFMG, 2004.

MENDES, Paulo Henrique A. Os gêneros discursivos em debate: análise de uma crônica de L. F. Veríssimo. In: MACHADO, Ida Lúcia; MELLO, Renato de. (orgs.). Gêneros: reflexões em análise do discurso. Belo Horizonte: NAD/POSLIN/ FALE-UFMG, 2004.

SOUZA, João Marcos C. de. O lapso na conversação como transgressão de gênero. In: MACHADO, Ida Lúcia; MELLO, Renato de. (orgs.). Gêneros: reflexões em análise do discurso. Belo Horizonte: NAD/POSLIN/FALE-UFMG, 2004. 


\section{ANEXO}

\section{Texto 1}

\section{Aperetivo*}

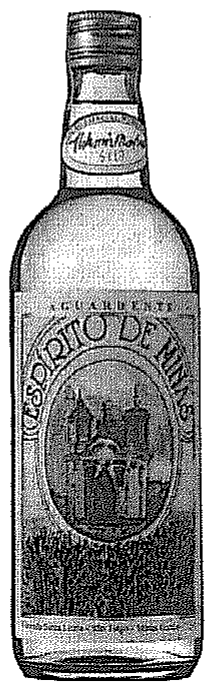

*Do latim aperctivu. Que abre ou estimula o apetite. Bebida espirituosa ingerida antes das refeições e que se faz, em geral, acompanhar de tira-gosto www.espiritodeminas.com.br À VENDA NAS MELHORES CASAS DO RAMO. Aprecie com moderação.

(Fonte: Almanaque Brasil de Cultura Popular, ago. 2003, com adaptaçōes)

\section{Texto 3}

ALINE - Adào turrusgarai
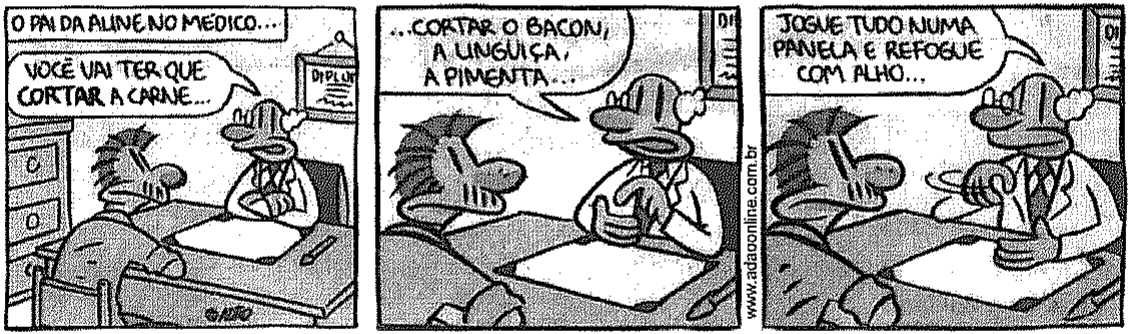

(Folha de S. Paulo, 27/10/04) 


\section{Texto 2}

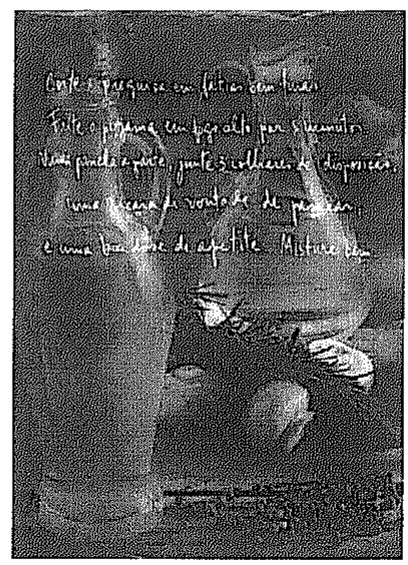

Corte a preguiça em fatias bem finas,

Frite o pijama em fogo alto por 5 minutos.

Numa panela a parte, junte 3 colheres de disposição,

uma xícara de vontade de passear,

e uma boa dose de apetite. Misture ben.

(Quem nountce SP - 26/11/04)

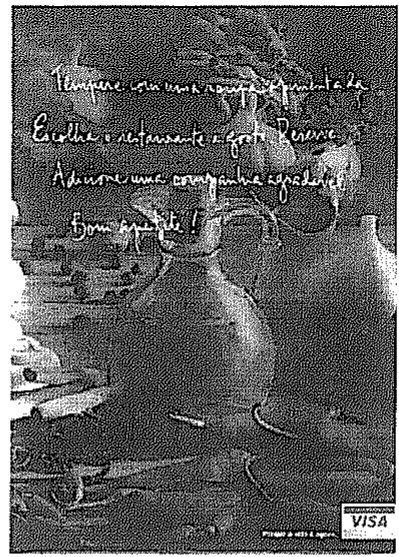

Tempere com uma roupa apimentada. Escolha o restaurante a gosto. Reserve. Adicione uma companhia agradável.

Bom apetite.

Porque a vida é agora. 